Article

\title{
User Involvement of People with Mild Disabilities in Technology Innovations: Does It Make a Difference?
}

\author{
Anita Borch * and Pål Strandbakken \\ Consumption Research Norway-SIFO, Oslo Metropolitan University, 0130 Oslo, Norway; \\ E-Mails: anitab@oslomet.no (A.B.), pals@oslomet.no (P.S.) \\ * Corresponding author
}

Submitted: 5 June 2018 | Accepted: 4 September 2018 | Published: 31 January 2019

\begin{abstract}
In this study, we explored the role of people with mild forms of visual, hearing, physical, and cognitive impairments in innovation processes. Our research questions are: do the product evaluations by people with mild disabilities differ from those given by people without reported disabilities? If so, how? The analysis is based on eight focus group interviews conducted in Norway in 2016, in which 60 participants were asked to evaluate 11 energy-efficient product ideas. Four of the focus groups (two of men and two of women) were recruited based on the criteria of being mildly disabled. The remaining groups (two of men and two of women) had no such clause. The research results are ambiguous, indicating that the evaluations of new innovation by mildly disabled people correspond with those made by people without reported disabilities in some aspects and differ in others. However, the small size of the sample studied in this article suggests that the research results must be regarded as preliminary. Overall, the study reveals some interesting observations to be confirmed and disconfirmed in further research.
\end{abstract}

\section{Keywords}

disability; energy products; focus group; innovations; product-evaluation

\section{Issue}

This article is part of the issue "People with Disabilities: The Overlooked Consumers", edited by Anita Borch and Kirsi Laitala (Consumption Research Norway-SIFO, Norway).

(C) 2019 by the authors; licensee Cogitatio (Lisbon, Portugal). This article is licensed under a Creative Commons Attribution 4.0 International License (CC BY).

\section{Introduction}

To contribute to a more sustainable society is a top priority in most European countries. To reduce the level of consumption, politicians can use several strategies. They can, for example, encourage consumers to reduce the level of consumption of products they already possess; to reorganize their consumer practices, for example, change from individually-based products to more collective (sharing-based) solutions; or to replace the products in use with more energy-efficient alternatives (Vitters $\varnothing$, Borch, Laitala, \& Strandbakken, 2015). So far, the third strategy seems to be preferred because it, in contrast to the first, is expected to both benefit the environment and stimulate the economy. As a result, a number of new technologies have been developed and launched in consumer markets.

The competition in consumer markets is, however, high, and to succeed, consumers are increasingly involved in innovation processes. As most of these processes involve early adopters or other consumer groups tending to be more technologically skilled than the general population, it has been argued that some of these innovations will fail because they require a higher level of technological skills than the general population possesses, and therefore are too difficult to obtain and use. Moreover, in order to lower the level of skills, it has been suggested to involve people with disabilities in innovation processes (Migliaccio, 2016, 2017; Noonan, $1997 / 2007)$. A basic assumption is that the involvement 
of disabled people in innovation processes will benefit not only disabled people but also the general population. In a study of young disabled people's use of mobile phones, Mi, Cavuoto, Benson, Smith-Jackson and Nussbaum (2014) found that the informants preferred bigger screens and more tactile technologies rather than touch screens. Most likely, these are results that people without disabilities can also relate to.

Even though the argument for involving people in innovation processes seems intriguing, it has, to our best knowledge, not been empirically explored. To date, studies addressing the role of disabled people in innovation processes have focused on innovations of assisting technologies and educational programs (see, for example, Bühler, 1996; Chiu, Liu, Hsie, \& Li, 2010; Joss, Cooclin, \& Oldenburg, 2016; Ward, Raphael, Clark, \& Raphael, 2016), whereas little attention has been paid to innovations of products targeting commercial, mass markets. To contribute to the ongoing knowledge development on userinvolvement in innovation processes, we will in this article explore the potential role of people with disabilities in the innovation of energy-efficient technologies directed towards mass markets. Our research questions are: does the product-evaluation carried out by disabled consumers differ from that of people without disabilities? If so, how? We start with two theoretical sections outlining previous research on user-involvement in innovation processes and explain why a study of the potential role of disabled people in this process is important. After a description of the methodology, we analyze the research questions and discuss the research results' contribution to previous research on user-involvement. In the last, concluding section, we present research gaps for further studies.

\section{User Involvement in Innovation Processes}

Creating a more sustainable society has been on the political agenda in most Western countries for decades. To achieve this goal, new technologies are constantly being developed and launched in consumer markets (Jacobsson, Bergek, \& Sandén, 2017). Critical to these technologies' success is the adoption of consumers (Noppers, Keizer, Bolderdijk, \& Steg, 2014). A successful adoption means, in short, that all phases in the innovation process are completed: (1) the acquisition of knowledge about the innovation, (2) forming an opinion about it, (3) deciding whether to accept or reject the idea, (4) the implementation of the decision, and (5) continuing the use of the product (Kowalska-Pyzalska, 2018). A significant part of all products that are developed and launched in consumer markets fail to complete this process, not necessarily because the consumers dislike the technologies, but because they have not heard about the products or do not know where to get them or how to use them. The market failures cause massive losses-for businesses that have invested in the technologies, for authorities who have supported the innovations, and for consumers who missed a chance to get a better product.
To reduce the risks of market failure, consumers have been increasingly involved in research and innovation processes over the last decades. The user involvement of consumers has been theorized and discussed in several studies (Bianchi, Benedetto, Franò, \& Frattini, 2017). Some of these studies are anchored in the seminar work of von Hippel (1994, 1998, 2005), and highlight the crucial role of users in innovation, and describe the innovation process in terms of distinct knowledge domains that producers and users possess. Producers possess knowledge about technical solutions, and users possess knowledge about their needs, the context of use, and their own capabilities as users. Both the knowledge of producers and the knowledge of consumers are characterized by "stickiness", that is, highly contextual and tacit knowledge that is difficult to transfer from one domain into another (von Hippel, 2005). Although designers and other actors representing the producers' side have certain representations of users in mind when they develop technologies, they usually fail to anticipate the practice of usage that eventually develops when the technologies are integrated into daily life (Akrich, 1995). Moreover, when technologies are in use, they are often misused or used in another way than anticipated (Rohracher, 2003, 2005). A frequently proposed solution to these problems is to intensify the interaction between producers and consumers. This can include producer participation in the consumer context, consumer participation in production, or consumer innovation (Heiskanen \& Lovio, 2010).

Consumers involved in innovations processes are often "early adopters" (Droge, Stanko, \& Pollitte, 2010). According to Rogers's (2003) theory, "early adopters" refers to the critical first market for the development and diffusion of new technologies. A basic assumption is that innovations tend to follow a bandwagon effect, where early adopters put pressure on later potential adopters to complete the adoption process. Hence, if early adopters accept or reject a technology, the technology will, respectively, succeed or fail. On the one hand, there are examples of innovations confirming this theory, such as the Sony Walkman, which became a success after being accepted by early adopters, and Google's Wave networking service, which became a failure after being largely rejected by early adopters (Bianchi et al., 2017). On the other hand, there are also examples of technologies that have failed despite being accepted by early adopters. Rather than grounding his theory on the bandwagon theory, Moore (1991) therefore suggests that early adopters have little or no influence on decisions made by later adopters.

As new technologies may fail to be transferred to other user groups, it has been argued that non-users are just as crucial, if not more so, in order to understand why some technologies fail to be successfully adopted. Nonuse is not merely the delayed uptake or the massive absence of use, but rather a choice with many dimensions and motivations. In a recent study of non-use of smart energy services in Finland, Kahma and Matschoss (2017) 
describe six types of non-use: (1) lagging adoption (temporary non-use), (2) active resistance (a steadfast non-use due to a number of reasons, for example lack of privacy, time, other technology preferences or moral conditions), (3) disenchantment (reluctant use often due to nostalgic feelings), (4) disenfranchisement (non-use due to a lack of physical or cognitive skills), (5) displacement (non-use due to an outsourcing of use often to other family members), and (6) disinterest (non-use due to lack of interest in new technology). The authors conclude that disinterest, disenchantment, and lagging adoption are the most common forms of non-use. However, disenfranchisement also plays a role when innovations are rejected.

\section{Why Study the Potential Role of People with Disabilities?}

As disenfranchisement is seldom addressed in studies of innovation targeting mass markets, in this article we will study consumer groups with visual, hearing, physical, or cognitive impairments. With one exception, the consumers are mildly disabled, meaning that they face some extra challenges in everyday life due to their disability, but not to the extent that they need extra assistance, except from special equipment like glasses and hearing-aids (for a more detailed description of disability see Table 2). Moreover, we will concentrate on consumers who are in stage $1-3$ of the innovation process, in which the consumers form their opinions about products and decide whether to continue the process. The product evaluations of disabled people will be compared to the product evaluations of people without reported disabilities. If they tend to make similar evaluations, their evaluations can be seen as representative of the general population; however, the argument for including them is weakened. If their evaluations tend to differ, they can be regarded as a consumer group with special evaluations; the argument for involving them is strengthened.

At this point, some specifications of the reasoning above need to be made. Firstly, all innovations do not necessarily require a higher level of skills than most people and, especially, early adopters possess. There are many examples of technologies that are easily used by most people, such as the earlier versions of televisions, which only have one button for "on" and "off". As such, there are two parallel narratives of the technological development going on: one, in which technology makes consumers' everyday lives easier, and another suggesting that it makes it all more complicated. In this research, we do not take a stand towards these narratives, but rather acknowledge that some technologies make everyday life easier, whereas others do not. Our concern is if, and to what extent, people with disabilities tend to use the products' required level of skills as an argument for and against adoption more frequently than abled consumers. If they do, it makes sense to involve them in innovation processes. If they do not, an important argument for including them weakens.
Secondly, and more importantly, people with disabilities are not necessarily lower-skilled technologically than the rest of the population. Rather, we find it reasonable to believe that some disabled people are as technologically skilled as able-bodied people, if not more so, because they use technologies to compensate for their disabilities. This assumption is, to some extent, supported by research conducted by Mi et al. (2014), showing that disabled young people use technologies in the same way as able young people (for example, playing music, listening to audiobooks, and using the calendar). Hence, what we are addressing here are not necessarily people with reduced technological skills, but with disabilities that may or may not have reduced technological skills. Again, the crux of the matters is whether they tend to use their disabilities as an argument for or against adoption. If they do, it makes sense to involve them in innovation processes. If they do not, an important reason for including them is lost.

Involving people with disabilities in innovation processes because they are assumed to reduce the level of required skills of new technologies to the level that most people possess is, however, not the only reason why we find these consumer groups particularly interesting. Other reasons are as follows:

1. Having some extra challenges related to mild forms of disability is a "normal" condition which many people deal with, either permanently or temporarily. There are no statistics available showing the exact percentage of people with mild disabilities. We know, however, that approximately $11 \%$ of the population in Europe is disabled (Thomson, 2016). The degree of disability, or whether the disability is permanent or temporary, is, however, not clearly stated. Most likely, people with mild or temporary forms of disabilities are not included. The percentage of disabled people will most likely increase in the years to come mainly due to an aging population (European Commission, 2015). People with disabilities, therefore, constitute a significant part of the population and should be taken into account in innovations targeting mass markets.

2. In contrast to other types of barriers consumers face in everyday life, disabilities are not a matter of choice, but a reality with which people have to cope in everyday life. The question is, therefore, not how consumers can adjust to new technologies, but rather how the technologies can be adjusted to the consumers. If people's hearing, visual, physical, and cognitive challenges are not taken into account in innovation processes, the technologies will most likely fail, simply because significant parts of the population cannot obtain or use them.

3. Despite representing a significant part of the population, little is known about disabled people as consumers (Borch, Kjørstad, \& Slettemeås, 2017; Borch, Slettemeås, \& Kjørstad, 2016a; 
Borch, Kjørstad \& Slettemeås, 2016b). Instead, researchers have created and institutionalized an "ablest" approach to consumer behavior, resulting in an idealized view of consumer reality since it overlooks various types of "consumer disadvantages" (Baker, 2006; Baker, Gentry, \& Rittenburg, 2005; Kaufman-Scarborough, 2015; Piacentini, Hibbert, \& Hogg, 2013; Woodliffe, 2007). Consequently, the voices of people with disabilities are seldom heard in product innovations. Markets are, in principle, open systems that should be accessible for all people (Slater \& Tonkiss, 2001). Hindering people from taking part in markets threatens fundamental needs, such as belongingness, self-esteem, control, and meaningful existence (Kaufman-Scarborough, 2015), and has been regarded as a violation of discrimination laws (Borch et al., 2016a). In essence, increasing disabled people's access to markets is about the right to be a full member of society.

4. Involving disabled people in innovation processes may be beneficial for businesses. Based on a literature review, Migliaccio (2017) concludes that diversity and disability management can contribute to the creation of a stimulating, motivating, and empowering working environment, and thereby maximize the overall performance of companies. Diversity and disability management can also boost tolerance with positive effects in terms of reputation and thereby increase companies' overall productivity. Migliaccio (2017) also concludes that the beneficial impact on the economic system is often overlooked and that disabled stakeholders who are customers or users represent a substantial and growing target for companies that produce specific goods and services and are tailoring their strategies according to demand.

5. Research indicates that people with moderate or severe disabilities have stronger needs for some consumer goods and services than people without disabilities. For example, people with physical impairments tend to have higher energy consumption than people without such disabilities because they spend more time at home and need higher indoor temperature due to their reduced mobility (Stewart \& Habgood, 2008). If properly designed, information and communication technologies (ICTs) can make the lives of disabled people easier, allowing them better interaction in society by widening their scope of activity, for example in education and employment (Migliaccio, 2016). Stronger needs for commercial products may be especially challenging for people with disabilities as they more often have low income due to a higher risk of being unemployed, working parttime, or being in low-paid work (Snell, Bevan, \& Thomson, 2014). In addition, products offered to segments with special needs may be more expen- sive than products offered to mass markets as they are more costly to produce (Migliaccio, 2017). The unfortunate combination of increased needs, reduced income, and higher prices may make disabled people a highly engaged consumer group with a special interest of being involved in innovation processes.

In this article, we explore the user-involvement of mildly disabled people in innovation processes based on their evaluations of product ideas combining two presumably high-involvement products for disabled people: energy and ICTs. The project on which the analysis is based will be described in the following section which addresses methodologies.

\section{Methodologies}

The research is part of the EU-funded project NATCONSUMERS, conducted from 2015 to 2017 involving ten partners from different European countries. The project aimed to facilitate the development of a "natural language". The natural language could be anything-a dimming light, a sudden sound, a text-triggering consumers to reduce their energy consumption at home.

In this article, the natural language is given in the form of product ideas developed by 15 young designers ( 20 to 30 years old) in a workshop conducted in London in September 2016. All ideas involved energy-efficient technologies, although in varying degrees. The designers were asked to develop products encouraging different kinds of consumer segments to change their behavior based on the consumers' gender, age, interests, etc. About 15 project partners and five to six representatives from the project's stakeholder group were available for the designers if they needed assistance in energy-related questions. About 20 ideas were developed.

At the end of the workshop, the designers, the project partners, and some of the project's invited stakeholders evaluated the ideas and gave their votes to the best ideas: 11 ideas stood out as better than the others. Table 1 provides an overview of the ideas.

In January 2017, the 11 ideas were evaluated by four focus groups. The focus groups were all recruited by a recruiting company and varying by gender and household income (over and under NOK 700' per year). A rough analysis of the data material showed, however, minor or no differences between men and women and households with high and low income. We, therefore, decided to arrange a second round of focus groups, this time including people with mild disabilities. In all, four focus groups of disabled people were conducted in June 2017, two of which composed by women and the remaining two by men. The recruiting procedure was the same as the previous time with one exception: In contrast to the first round of focus groups, the second round only included people who responded positively on the question: do you have any forms of disabilities, i.e., visual 
Table 1. The 11 product ideas evaluated. Source: Bent, Dromacque, Kmetty, Grigorou and Mikkelsen (2017).

\begin{tabular}{ll}
\hline Product ideas & Description of products \\
\hline $\begin{array}{l}\text { Individual } \\
\text { technologies }\end{array}$ & Technologies tending to be directed towards individual consumers
\end{tabular}

Doctor appliance (Dr. App)

Interactive

Energy Story

Platform

Feeding Your

Appliances

I challenge you

Family
technologies

Energy Frame

ThunderFly

Energy Saving

Platform
E-Pooling

Dr. App is an app that allows you to have a full scan of the state of your appliances. It provides you with suggestions for improving the life of your appliances, detects if there are any irregularities, gives you a recommendation on your usage and when it is time to buy another one, shows you other appliances on the market with a detailed analysis and all possible incentives and discounts available.

The Interactive Energy Story platform provides its users with unique stories based on the energy consumption of the household through a code on their bill. Users receive a new chapter of these short novels every month. In the background, issues concerning ecology, sustainability, responsible consumption, etc. help to raise awareness about energy savings and green living.

The app simplifies household energy management: the kWh are translated into units like "energy Lego bricks". You can allocate your energy units to each of your appliances or reorganize your units according to advice on energy saving. Understanding energy management through reallocating units between your household appliances is very simple. Saved units can be stored for upcoming months or given to charities.

An app that provides you with interactive visualization of your energy consumption by being connected to your smart meter. It is an intuitive and visual interpretation of data that makes it possible for you to surf through the data in different ways. It also informs you how to work better on your energy consumption. There is the possibility of adding your friends and family to see how your community is working on their energy consumption.

Technologies tending to be directed towards households

Energy Frame is a visual representation of your energy consumption through a tree-the more you save, the more the tree evolves and flourishes. People can join others and create a forest of trees and get tips and advice on how to reduce consumption. It can go from a decorative and contemplative image to a more interactive game.

The ThunderFly is a little object which reflects energy consumption through visual information. The ThunderFly glows, showing the on-going consumption of the household. When it glows more vividly it means consumption is getting higher and you should verify what is going on through the app of your mobile. The ThunderFly is a gentle reminder of family energy consumption. Every month the ThunderFly delivers the family energy report.

Cooperative Technologies tending to be directed towards cooperatives
technologies

The Energy Saving Community Platform is a digital platform where groups of consumers can team up to save money by reducing their household energy consumption. The money saved goes into a common fund to be used for community projects. Community meetings and workshops allow members to define projects they wish to create and to learn about consumption and to share tips and tricks on energy saving.

E-Pooling is a social platform targeting single households, people seeking company and older individuals to engage in shared interests and activities. By socializing, users reduce their energy consumption. Indeed, they gather in one place and use only the appliances of that space for collective purposes.

\section{Children's technologies}

Technologies tending to be directed towards children

Energyland

An educational system of challenges for children that aims to teach them and raise their awareness on energy saving and careful energy consumption. There are different challenges children can unlock by practicing careful energy consumption at home. The system is managed by teachers who send challenges to kids and give them physical badges that can be shown in class and help stimulate the competition among children and schools. 
Table 1. (Cont.) The 11 product ideas evaluated. Source: Bent, Dromacque, Kmetty, Grigorou and Mikkelsen (2017).

\begin{tabular}{ll}
\hline Product ideas & Description of products \\
\hline Children's & Technologies tending to be directed towards children \\
technologies &
\end{tabular}

Housemonsters

Housemonster is an augmented reality app which allows end-users to save energy by engaging with their 'house monster', which represents energy incongruences of the devices. Parents and kids will have family monster assistance which will send push notifications when some actions can be taken in order to save energy.

Piggy bank A piggy bank is an app showing children how much money they save by changing their family energy consumption habits. It makes energy saving simple and engaging for kids because it makes it tangible. By making immediate changes such as switching off the lights, their piggy bank shows them how much they're saving. The saved energy makes the difference in kids' pocket money and engages them in saving more.

or hearing impairments, or physical or cognitive disabilities? Notably, we do not know if the participants of the first groups have some kind of disability. As some of them might be disabled, the difference between the "disabled" and the "able" are probably more diffuse than it could have been if the participants recruited in the first round had answered negatively in the same question.

Participants were given a free meal (pizza and lemonade) and NOK 500 ' in gift certificates. The sample may, therefore, be slightly biased in terms of including people that are either interested in residential energy consumption, or like the idea of getting a free meal and some extra income. The focus groups included 5 to 10 participants. Table 2 provides an overview of the focus group participants included in the analysis's sample.

As shown in Table 1, most participants were between 40 and 60 years old, highly educated (12+ years of education) and work full time (cf. Snell et al., 2014). The number of participants not working full time is higher in the focus groups with disabled people, especially in one of the focus groups composed by men with disabilities (MD1). The only participant who was severely disabled was a member of group MD1. Although this group stood out as more critical than the others (see Table 3), the man was not more critical than the most talkative members of the group. Most likely, his severe impairment did not affect the group discussion.

The aims of the focus groups were: (1) to examine participants' evaluation of the product ideas' presumed product qualities and their chance of being purchased and used by themselves or their families, and, hence, (2) to identify the product ideas with the highest potential to reduce residential energy consumption. The main questions were: do the participants report that the products would be purchased and used by them or their family in short and longer terms? Why? The focus group design followed seven main steps:

1. The moderators introduce the project and the participants introduce themselves;

2. The participants talk about the residential energy consumption of their households;
3. The moderators present the product ideas visually and orally by showing a PowerPoint presentation and describing the content;

4. The participants get a handout of the product ideas and study the ideas individually with assistance, if needed, from the moderators;

5. The participants discuss the product ideas together, one by one, and agree on whether they are basically positive, negative or both positive and negative;

6. The focus groups close.

Each focus group took two hours and took place at SIFO. All groups were moderated by the researchers. When the product ideas were presented, the participants were instructed to ignore the fact that some of the product ideas were based on technologies that had not been developed or were unknown to the focus group participants. Rather, they should talk as if all the technologies were available. The moderators made sure that all participants understood all of the tasks and questions and had a chance to make their voices heard.

The analysis was conducted in three main steps. First, we categorized the eleven product ideas. As shown in Table 1, we divided the ideas into four categories: individual-oriented technologies, family-oriented technologies, cooperative technologies and children's technologies.

In the next step, we mapped the positive, negative, or ambivalent opinions about the product ideas that the participants had agreed upon during the focus group. In Table 3, positive and negative evaluations are given 2 and 0 points, respectively. Product ideas, for which no agreements were reached were regarded as neither positive nor negative and given 1 point.

Finally, we registered all arguments for and against each idea and divided them into nine categories: cultural/practical, educational, technological, social, emotional, esthetical, environmental, economic, health, and moral (see Table 4). We also made a table showing the number of times each argument had been voiced. However, as this table is too encompassing to be shown 
Table 2. The four samples by disability, income, age, education, and position.

\begin{tabular}{|c|c|c|c|c|}
\hline & Disability/income & Age & Education & Position \\
\hline \multirow[t]{7}{*}{ Women, disabled 1 (WD1) } & Physical & 28 & High & Full time \\
\hline & Physical & 46 & High & Unemployed \\
\hline & Physical & 52 & High & Disabled \\
\hline & Visual & 33 & High & Full time \\
\hline & Visual & 28 & High & Full time \\
\hline & Hearing & 45 & High & Full time \\
\hline & Cognitive & 59 & High & Full time \\
\hline \multirow[t]{7}{*}{ Women, disabled 2 (WD2) } & Physical & 52 & High & Disabled \\
\hline & Physical & 61 & Middle & Disabled \\
\hline & Physical & 65 & High & Pensioner \\
\hline & Visual & 60 & High & Full time \\
\hline & Cognitive & 29 & High & Full time \\
\hline & Cognitive & 23 & Middle & Full time \\
\hline & Cognitive & 29 & High & Full time \\
\hline \multirow[t]{8}{*}{ Men, disabled 1 (MD1) } & Physical & 57 & High & Disabled \\
\hline & Hearing & 35 & High & Full time \\
\hline & Visual & 65 & High & Pensioner \\
\hline & Cognitive & 43 & Low & Disabled \\
\hline & Hearing & 63 & High & Full time \\
\hline & Visual & 46 & High & Full time \\
\hline & Physical & 50 & Middle & Full time \\
\hline & Cognitive & 41 & Middle & Full time \\
\hline \multirow[t]{10}{*}{ Men, disabled 2 (DM2) } & Physical & 57 & High & Full time \\
\hline & Visual/hearing & 39 & Middle & Disabled \\
\hline & Physical & 65 & Middle & Pensioner \\
\hline & Physical/Hearing & 56 & Low & Disabled \\
\hline & Physical/visual & 49 & Middle & Disabled \\
\hline & Visual & 52 & Low & Unemployed \\
\hline & Cognitive & 35 & High & Part-time \\
\hline & Hearing & 63 & High & Full time \\
\hline & Physical/hearing & 44 & High & Disabled \\
\hline & Cognitive & 53 & High & Part-time \\
\hline \multirow[t]{8}{*}{ Women, low income (WLI) } & NOK 200' /399' & 29 & High & Full time \\
\hline & NOK 400' /499' & 34 & High & Full time \\
\hline & NOK 400' /499' & 49 & High & Full time \\
\hline & NOK 200'/399' & 46 & High & Part-time \\
\hline & NOK 500'/599' & 57 & High & Full time \\
\hline & NOK 400' /499' & 41 & High & Full time \\
\hline & NOK 400' /499' & 54 & High & Full time \\
\hline & NOK 400' /499' & 61 & Middle & Part-time \\
\hline \multirow[t]{5}{*}{ Women, high income (WHI) } & NOK 1,2 mill & 52 & & Full time \\
\hline & NOK 800' & 42 & High & Full time \\
\hline & NOK 1,1 mill & 51 & & Full time \\
\hline & NOK 1,1 mill & 43 & & Full time \\
\hline & NOK 990' & 38 & High & Full time \\
\hline \multirow[t]{7}{*}{ Men, low income (MLI) } & NOK 400' /499' & 46 & High & Full time \\
\hline & NOK 500'/599' & 45 & High & Full time \\
\hline & NOK 500'/599' & 49 & High & Full time \\
\hline & NOK 500'/599' & 50 & High & Full time \\
\hline & NOK 600'/999' & 53 & Middle & Full time \\
\hline & NOK 600'/999' & 35 & High & Full time \\
\hline & NOK 500'/599' & 63 & Middle & Part-time \\
\hline
\end{tabular}


Table 2. (Cont.)The four samples by disability, income, age, education, and position.

\begin{tabular}{|c|c|c|c|c|}
\hline & Disability/income & Age & Education & Position \\
\hline \multirow[t]{8}{*}{ Men, high income (MHI) } & NOK 1 mill & 38 & & Full time \\
\hline & NOK 1,3 mill & 50 & & Full time \\
\hline & NOK 1,2 mill & 49 & High & Full time \\
\hline & NOK 1,1 mill & 47 & High & Full time \\
\hline & NOK 1,1 mill & 58 & High & Full time \\
\hline & NOK 1,6 mill & 52 & & Full time \\
\hline & NOK 1 mill & 52 & High & Full time \\
\hline & NOK 1,1 mill & 44 & High & Full time \\
\hline
\end{tabular}

within the scope of this paper, we made a brief version of it showing the number of times each category of arguments had been expressed (see Table 5). All in all, 242 arguments were identified. Note that Table 5 does not show how many times each argument within a category of arguments was mentioned, nor does it show the length and intensity of the different arguments. We believe, however, that the table, all in all, provides a valid overview of the different arguments used in the participants' evaluation of the product ideas.

\section{Preferred Ideas}

So far, we have described the theory and methodology on which this article is based. In this section, we present the main results of the analysis. Table 3 shows the focus groups' evaluation of the product ideas.

Table 3 indicates that people with mild disabilities tend to have lower preferences for individual-oriented energy-efficient technologies and higher preferences for cooperative oriented energy-efficient technologies. Why people with mild disabilities are more collectively oriented than others is hard to tell based on the information available. One hypothesis might be that there were more singles in the sample of people with disabilities, which may increase the preference for collective solutions. However, if more participants were single, we might expect that they would largely prefer individually oriented product ideas than people without mild disabilities, which is not the case.

Table 3 also indicates that men with disabilities tend to have lower preferences for new energy-efficient technologies. Interestingly, in one of the focus groups (MD1), none of the product ideas were positively evaluated. This group was not the group with the highest numbers of unemployed. As such, the result does not reflect that the members of this group are more likely to refuse products due to low-income.

Table 3. Participants' preferences related to new, energy-efficient technologies by disability, gender, and economic income.

\begin{tabular}{|c|c|c|c|c|c|c|c|c|c|c|}
\hline \multirow{2}{*}{ Product ideas } & \multicolumn{10}{|c|}{ Participants' evaluations } \\
\hline & WD1 & WD2 & MD1 & MD2 & Tot & WLI & WHI & MLI & MHI & Tot \\
\hline Individual technologies & 6 & 0 & 1 & 2 & 9 & 2 & 4 & 5 & 4 & 15 \\
\hline Dr App & 2 & 0 & 1 & 1 & 4 & 0 & 0 & 2 & 1 & $3(7)$ \\
\hline Interactive energy stories & 0 & 0 & 0 & 0 & 0 & 0 & 0 & 0 & 1 & $1(1)$ \\
\hline Feeding your appliances & 2 & 0 & 0 & 0 & 2 & 2 & 2 & 2 & 0 & $6(8)$ \\
\hline I challenge you & 2 & 0 & 0 & 1 & 3 & 0 & 2 & 1 & 2 & $5(8)$ \\
\hline Family technologies & 3 & 3 & 1 & 4 & 11 & 4 & 4 & 3 & 2 & 13 \\
\hline Energy frame & 2 & 1 & 1 & 2 & 6 & 2 & 2 & 1 & 0 & $5(11)$ \\
\hline Thunderfly & 1 & 2 & 0 & 2 & 5 & 2 & 2 & 2 & 2 & $8(13)$ \\
\hline Cooperative technologies & 2 & 2 & 2 & 1 & 7 & 1 & 2 & 0 & 1 & 4 \\
\hline Energy saving platform & 2 & 2 & 1 & 0 & 5 & 1 & 1 & 0 & 0 & $2(7)$ \\
\hline E-pooling & 0 & 0 & 1 & 1 & 2 & 0 & 1 & 0 & 1 & $2(4)$ \\
\hline Children's technologies & 4 & 4 & 0 & 6 & 14 & 2 & 6 & 4 & 4 & 16 \\
\hline Energyland & 2 & 2 & 0 & 2 & 6 & 0 & 2 & 2 & 2 & $6(12)$ \\
\hline Housemonsters & 1 & 0 & 0 & 2 & 3 & 2 & 2 & 0 & 0 & $4(7)$ \\
\hline Piggy bank & 1 & 2 & 0 & 2 & 5 & 0 & 2 & 2 & 2 & $6(11)$ \\
\hline Total & 15 & 9 & 4 & 13 & 41 & 9 & 16 & 12 & 11 & 48 \\
\hline Gender diff & 24 & & 17 & & & 25 & & 23 & & \\
\hline
\end{tabular}

Note: 0 = negatively evaluated; 1 = negatively/positively evaluated; 2 = positively evaluated. 


\section{Arguments for and against Adoption}

Although the preferences are the same, the reasons behind these preferences may differ. Table 4 provides an overview of the arguments "for" and "against" behind the participants' evaluations.

Table 4 shows that there were arguments both for and against adoption of different kinds: cultural/ practical, educational, technical/conceptual, social, emotional, esthetical, environmental, economic, health, and moral/juridical. Overall, there were more negative than positive arguments for or against adoption, which underlines the importance of non-use studies (cf. Kahma \& Matschoss, 2017). Table 5 shows the number of times each focus group mentioned one type of argument for and against adoption. As shown in Table 5, some of these arguments were more frequently voiced than others.

Table 5 indicates that arguments for or against adoption, to some extent, vary between people with and without reported disabilities. The table shows that peo-

Table 4. Arguments for and against adoption of product ideas.

\begin{tabular}{lll}
\hline & Arguments for (positive arguments) & Arguments against (negative arguments) \\
\hline Cultural/ & - Covers a need & - Covers no need/not beneficial enough \\
practical & - Possible to develop, cultural conditions & - Already exist \\
& considered & - Not practical use. Does not work in \\
& & practice/not part of our socialization \\
& & - Unrealistic, cultural conditions considered
\end{tabular}

\begin{tabular}{ll}
\hline Educational & - Raises awareness \\
& - Informative, including pedagogical \\
& - Visualizes your consumption \\
& - Creates a sense of achievement \\
& - Enables users to compete individually \\
& (with themselves) \\
\hline Technological & - User-friendly \\
or conceptual & - Universal Design (for example, "Not too \\
functionality & loud-to please people with hearing \\
(Te) & impairments") \\
& - Smart (technically innovative)
\end{tabular}

Demands too much technical skills

- Informative, including pedagogical

- Enables users to compete individually

- Self-effacing. The product makes itself superfluous when used ("When you have used it, you no longer need it")

- Does not benefit users: the one who saves money is not the same as the one who gets the benefits

- Target wrong users: the target groups (for example, children) are not in charge of the household's energy consumption

- Wrong motive. May save energy, but for other reasons

- Inexplicable. Not clear how it works

- May involve data privacy problems

\begin{tabular}{lll}
\hline Social & - Meet people & - Mayfly (gets unfashionable quite soon) \\
(So) & - Fits all people & - Creates social pressure by visualizing users \\
& - Fashionable & consumption \\
& - Provides social status by making your energy & - Creates pillories by visualizing users \\
& consumption visible & consumption \\
& - Enables users to compete socially (with & - Reveals social differences by visualizing users \\
& others) (N) & consumption \\
& - Creates social pressure by visualizing users & - Enables users to compete socially (with others) \\
& consumption & - Risk of free-riders \\
& & - Conflicting \\
\hline Emotional & - Likes it & - Dislikes it \\
(Em) & - Fun (for example, for kids) & - Not fun (for example, boring over time) \\
& - Nostalgic (“It reminds me of the & - Annoying/distracting \\
& thermometers my grandparents and parents & \\
\hline Esthetical & used to have in the 70s”) & \\
(Es) & Decorative & \\
\hline
\end{tabular}


Table 4. (Cont.) Arguments for and against adoption of product ideas.

\begin{tabular}{|c|c|c|}
\hline & Arguments for (positive arguments) & Arguments against (negative arguments) \\
\hline $\begin{array}{l}\text { Environmental } \\
\text { (En) }\end{array}$ & & $\begin{array}{l}\text { - Inefficient, i.e. does not save enough energy } \\
\text { in the household } \\
\text { - Does not save enough energy in a product's } \\
\text { service life } \\
\text { - Vulnerable for rebound effects: The money/ } \\
\text { extra money you got due to your energy } \\
\text { saving is used on energy-demanding } \\
\text { consumption }\end{array}$ \\
\hline $\begin{array}{l}\text { Economic } \\
\text { (Ec) }\end{array}$ & Save money & $\begin{array}{l}\text { - The product would most likely be too } \\
\text { expensive } \\
\text { - The product provides pester power } \\
\text { - "Commercial". Information that might have } \\
\text { been offered by a commercial sender }\end{array}$ \\
\hline $\begin{array}{l}\text { Health } \\
\text { (He) }\end{array}$ & & - Deactivating \\
\hline $\begin{array}{l}\text { Moral/juridical } \\
\text { (Mo) }\end{array}$ & Good cause & $\begin{array}{l}\text { - Distracting. Takes your attention away from } \\
\text { more important things in life } \\
\text { - Wrong motive. May save energy, but not for } \\
\text { the environment, not to save money } \\
\text { - Materialism ("this is just another thing...") } \\
\text { - Information panic (too much information) } \\
\text { - Data privacy (who gets the information) }\end{array}$ \\
\hline
\end{tabular}

ple with reported disabilities made more arguments for and against the adoption than people without disabilities (131 versus 111 arguments).

In both groups, emotional arguments are most frequently voiced, especially "likes it". The emotional arguments were more frequently used by people without disabilities (33 versus 21). Also, social and educational arguments were frequently voiced. Whereas social arguments were expressed equally by both groups, educational arguments were more frequently voiced by people with disabilities (29 versus 19 ).

Table 5 also indicates that people with reported disabilities seem to have more moral arguments against adoption (1 versus 10 arguments). The most frequent moral argument for adoption was "good cause", whereas the most frequent negative arguments were "distracting" (the idea takes attention away from more important things in life) and "wrong motive" (the proposed product may save energy, but for other reasons than concern for the environment). Typically, participants argued that Piggy bank taught children to save energy for economic rather than environmental reasons.

People with disabilities also voiced more technical arguments against adoption (12 versus 8 ) than able participants. Most frequently, the participants did not understand how the product worked.

In the analysis of preferred product ideas, men with disabilities stood out as more negative towards the new ideas than others. This tendency can also be observed in Table 5, where disabled men gave eight arguments for and 16 arguments against adoption.

Other results worth mentioning do not seem to be related to the participants' disability. One of them is that emotional arguments are more frequently expressed in the discussion about the most and the least popular preferred products idea, Thunderfly and Energy stories, respectively, than in discussions about other product ideas. The most frequent argument for adopting Thunderfly was "likes it". Interestingly, nostalgic feelings were mentioned six times as an argument for adopting this application. None of the other product ideas seemed to arouse such feelings.

Social and cultural/practical arguments are more frequently expressed regarding the cooperatively oriented product ideas (Energy-saving platform and E-pooling). Many participants valued the social aspect of these ideas but believed that Norwegians are not ready for sharing economy mainly due to an individualized culture.

The educational aspects of the product ideas were most frequently expressed in discussions about the individually oriented technologies (for example Feeding Your Appliances and I Challenge You) and children-oriented technologies (especially Energyland). Whereas the informative aspect was highlighted in the former, the upraising potential was highlighted in the latter.

Economic arguments were most frequently expressed in the discussion about Dr. App and Energyland, where the groups of women with disabilities and with low 
Table 5. The frequency of the arguments for (P) and against $(\mathrm{N})$ adoption of product ideas, by type of argument.

\begin{tabular}{|c|c|c|c|c|c|c|c|c|c|c|c|c|c|c|c|c|}
\hline \multirow[t]{3}{*}{ Product ideas } & \multicolumn{16}{|c|}{ Arguments } \\
\hline & \multicolumn{2}{|c|}{ WD1 } & \multicolumn{2}{|c|}{ WD2 } & \multicolumn{2}{|c|}{ MD1 } & \multicolumn{2}{|c|}{ MD2 } & \multicolumn{2}{|c|}{ WLI } & \multicolumn{2}{|c|}{ WHI } & \multicolumn{2}{|c|}{ MLI } & \multicolumn{2}{|c|}{ MHI } \\
\hline & $P$ & $\mathrm{~N}$ & $P$ & $\mathrm{~N}$ & $P$ & $\mathrm{~N}$ & $P$ & $\mathrm{~N}$ & $P$ & $\mathrm{~N}$ & $P$ & $\mathrm{~N}$ & $\mathrm{P}$ & $\mathrm{N}$ & $P$ & $\mathrm{~N}$ \\
\hline \multicolumn{17}{|c|}{ Individual technologies } \\
\hline \multirow[t]{5}{*}{ Dr. App } & $\mathrm{Cu}$ & Ec & $\mathrm{Ed}$ & Em & $\mathrm{Ed}$ & Ec & $\mathrm{Ed}$ & $\mathrm{Cu}$ & Em & $\mathrm{Te}$ & & En & Em & & $\mathrm{Em}$ & En \\
\hline & $\mathrm{Ed}$ & & & $\mathrm{Te}$ & & & Em & & $\mathrm{Ed}$ & So & & & $\mathrm{Cu}$ & & $\mathrm{Ed}$ & \\
\hline & $\mathrm{Ed}$ & & & Ec & & & & & $\mathrm{Cu}$ & Ec & & & Ed & & & \\
\hline & & & & Ec & & & & & & Ec & & & & & & \\
\hline & & & & En & & & & & & & & & & & & \\
\hline \multirow{2}{*}{$\begin{array}{l}\text { Interactive Energy } \\
\text { Stories }\end{array}$} & & $\mathrm{Te}$ & $\mathrm{Em}$ & Em & & Em & & $\mathrm{Te}$ & & $\mathrm{Em}$ & & & & $\mathrm{Em}$ & & Te \\
\hline & & & & Te & & $\mathrm{Cu}$ & & & & & & & & $\mathrm{Cu}$ & & \\
\hline \multirow{3}{*}{$\begin{array}{l}\text { Feeding Your } \\
\text { Appliances }\end{array}$} & $\mathrm{Ed}$ & & $\mathrm{Ed}$ & $\mathrm{Te}$ & & $\mathrm{Cu}$ & & $\mathrm{Te}$ & $\mathrm{Ed}$ & $\mathrm{Te}$ & $\mathrm{Ed}$ & Em & & $\mathrm{Cu}$ & $\mathrm{Em}$ & \\
\hline & So & & & $\mathrm{Te}$ & & Mo & & & $\mathrm{Ed}$ & & & $\mathrm{Ed}$ & & $\mathrm{Te}$ & & \\
\hline & $\mathrm{Ed}$ & & & & & & & & & & & $\mathrm{Cu}$ & & & & \\
\hline \multirow[t]{4}{*}{ I Challenge You } & $\mathrm{Ed}$ & So & & $\mathrm{Ed}$ & $\mathrm{Te}$ & So & $\mathrm{Ed}$ & $\mathrm{Cu}$ & So & So & $\mathrm{Em}$ & Em & & $\mathrm{Cu}$ & $\mathrm{Em}$ & Ec \\
\hline & So & & & & Ed & $\mathrm{Cu}$ & & So & & & So & & & & & Mo \\
\hline & $\mathrm{Ed}$ & & & & $\mathrm{Ed}$ & & & Mo & & & & & & & & \\
\hline & $\mathrm{Ed}$ & & & & & & & & & & & & & & & \\
\hline \multicolumn{17}{|l|}{ Family Technologies } \\
\hline \multirow[t]{5}{*}{ Energy Frame } & En & $\mathrm{Cu}$ & $\mathrm{Em}$ & En & Em & Mo & $\mathrm{Ed}$ & Ec & Em & & Es & Es & & So & $\mathrm{Em}$ & So \\
\hline & So & & $\mathrm{Ed}$ & $\mathrm{Te}$ & Em & & & & $\mathrm{Ed}$ & & So & & & En & $\mathrm{Te}$ & \\
\hline & Es & & So & Es & & & & & & & $\mathrm{Em}$ & & & & & \\
\hline & $\mathrm{Ed}$ & & $\mathrm{Em}$ & So & & & & & & & & & & & & \\
\hline & $\mathrm{Ed}$ & & & & & & & & & & & & & & & \\
\hline ThunderFly & $\mathrm{Em}$ & Mo & $\mathrm{Em}$ & Es & Em & $\mathrm{Te}$ & $\mathrm{Ed}$ & Mo & Em & & $\mathrm{Ed}$ & $\mathrm{Ed}$ & $\mathrm{Ed}$ & & $\mathrm{Em}$ & \\
\hline & So & & & & & & & & Es & & $\mathrm{Em}$ & & Em & & $\mathrm{Em}$ & \\
\hline & & & & & & & & & $\mathrm{Ed}$ & & & & Em & & & \\
\hline Cooperative Techn & gies & & & & & & & & $\mathrm{Em}$ & & & & & & & \\
\hline Energy Saving & $\mathrm{Em}$ & $\mathrm{Cu}$ & $\mathrm{Cu}$ & $\mathrm{Cu}$ & So & $\mathrm{Te}$ & So & So & So & En & So & $\mathrm{Cu}$ & & $\mathrm{Cu}$ & & So \\
\hline Platform & $\mathrm{Cu}$ & So & $\mathrm{Cu}$ & $\mathrm{Te}$ & & So & Mo & & & $\mathrm{Cu}$ & So & Em & & So & & Te \\
\hline & Ec & $\mathrm{Cu}$ & & En & & So & & & & So & & $\mathrm{Cu}$ & & So & & So \\
\hline & So & So & & & & & & & & $\mathrm{Cu}$ & & & & & & \\
\hline E-Pooling & So & $\mathrm{Cu}$ & So & Mo & & $\mathrm{Cu}$ & So & $\mathrm{Te}$ & So & $\mathrm{Cu}$ & So & En & & $\mathrm{Cu}$ & So & \\
\hline & Mo & $\mathrm{Ed}$ & Em & $\mathrm{Ed}$ & & & & & & & & & & & & \\
\hline & So & En & & & & & & & & & & & & & & \\
\hline Children Technolog & & $\mathrm{Ed}$ & & & & & & & & & & & & & & \\
\hline Energyland & $\mathrm{Em}$ & & $\mathrm{Em}$ & En & & $\mathrm{Te}$ & $\mathrm{Ed}$ & & $\mathrm{Em}$ & Em & $\mathrm{Em}$ & So & $\mathrm{Em}$ & & & \\
\hline & $\mathrm{Ed}$ & & $\mathrm{Ed}$ & & & & So & & $\mathrm{Ed}$ & So & So & & & & & \\
\hline & $\mathrm{Ed}$ & & $\mathrm{Ed}$ & & & & & & $\mathrm{Ed}$ & & En & & & & & \\
\hline & & & & & & & & & $\mathrm{Em}$ & & & & & & & \\
\hline & & & & & & & & & So & & & & & & & \\
\hline Housemonsters & $\mathrm{Em}$ & $\mathrm{He}$ & $\mathrm{Em}$ & Ec & & Mo & $\mathrm{Em}$ & & $\mathrm{Em}$ & & $\mathrm{Em}$ & So & Em & $\mathrm{Cu}$ & $\mathrm{Em}$ & Te \\
\hline & & Mo & & $\mathrm{Te}$ & & & $\mathrm{Ed}$ & & $\mathrm{Ed}$ & & $\mathrm{Ed}$ & Em & & & & \\
\hline & & & & & & & Ed & & $\mathrm{Cu}$ & & & & & & & \\
\hline & & & & & & & & & Em & & & & & & & \\
\hline Piggy Bank & & Mo & $\mathrm{Em}$ & & & Mo & $\mathrm{Em}$ & & & En & $\mathrm{Ed}$ & $\mathrm{Te}$ & $\mathrm{Em}$ & & $\mathrm{Ed}$ & \\
\hline & & & & & & & & & & & & & Em & & & \\
\hline
\end{tabular}


income emphasized the extra costs of replacing old technologies with new and more sustainable technologies:

I think that if this [Dr. App] told us that this [apparatus] does not function anymore, it will put a pressure on households. I know that my refrigerator and freezer are not new, but I can't afford to buy a new one. Should I feel bad because of this? Nowadays, you are expected to change to more efficient applications to save the environment or reduce your energy bill, but we can't replace our refrigerator because we can't afford it. It all depends on where you are in life, your social premises, it is not 'only' about replacing things. (Women with disabilities)

A similar argument was made by a woman with low income, who worried that children living in poor households would be victims of the extra costs of adopting energy-efficient products:

This [Energyland] shall be used in schools. It will be shown to everybody. Not all have the same financial premises, which implies that some will have better opportunities to save energy than others. It costs NOK 250' to replace a led lamp, so it can be quite expensive. Not all can afford this. Such things need to evolve gradually. Children [from low-income families] have to stand in front of their classmates and tell them that we can't afford to save energy. I don't like it. (Women with low income)

Only two women used disability as an argument for or against adoption. One of these comments addressed hearing impairment:

Good for people with hearing impairments...if you can turn the sound up and down. I never turn the sound up too much since I have hearing problems. (Women with hearing impairment, in a discussion about Thunderfly)

The other comment using disability as an argument addressed cognitive and visual impairment:

It is easy to understand for everybody. No difficult explanations. It is easier with pictures for those who think that text is difficult. (Women with physical impairments, in a discussion about Feeding Your Appliances)

Neither disabled women nor disabled men tended to use technical skills as an argument for or against adoption of the 11 products. The closest we got was a disabled woman who commented on the sharing economical idea, E-pooling, suggesting that old people would not dare use their neighbors' washing machines if they were allowed to, as they could not understand which button to push. The relevance of this argument was, however, demonstrated several times by both participants with and without disabilities. For example, the following conversation took place in phase 2 of the focus group of lowincome men:

Man 1: I am so unconscientious because we have these very nice ADAX furnaces at home which can reduce the indoor temperature at night if they are activated.

Man 2: Same! We also have ADAX furnaces, which we haven't programmed the last two years.

Man 1: Yes, I do not know how to program them.

Man 2: Yes, it is difficult.... If you make mistakes, you have to do it all again, plot in all the days, plus the time when the temperature should increase and decrease during the day.

Overall, we regard the dialog above as an illustrative example confirming previous research indicating that some technological innovations offered in consumer markets today require a higher level of technical skills than most people possess.

So far, we have presented the main results of the study. The next question is what these results add to previous studies of user involvement.

\section{Discussion: The Study's Contribution to User-Involvement Studies}

Most studies of user involvement focus on able consumers, or, although less frequently, people with moderate or severe disabilities. In this study, we have, however, addressed people with mild impairments. The study indicates that product evaluations made by mildly disabled people, to some extent, are similar to those made by people without reported disabilities, and in some respect differ. For example, both people with and without reported disparities liked Thunderfly best and Energy Stories least. Their corresponding product preferences were probably the result of shared culture-historical roots. Symptomatically, Thunderfly was the only product idea arousing nostalgic feelings in both groups, apparently because it reminded the participants about their childhood in the 1970s when their parents or grandparents had a meter hanging on the wall showing the household's energy consumption. When an arrow in this meter entered a red zone, the energy price increased. The production of the meter stopped when price differentiation during the day was abolished. Still, more than four decades later, a similar metering seems to create nostalgic feelings among consumers, disabled or not.

On the other hand, there are observations indicating that there are differences between people with, and without, mild forms of disabilities. One of the observations worth noticing is that people with disabilities tend to articulate more arguments for and against the adoption of new products than people without reported disabilities. This is in line with previous research indicating that people with disabilities represent a highly engaged 
consumer group due to an unfortunate combination of increased needs, reduced income, and higher prices for products for people with special needs (see section 3, point 5).

Another observation indicating differences is that technical arguments were more frequently voiced by people with disabilities, their main concern being that they did not understand how the product worked. This observation confirms the assumption on which this study is based, namely that user-involvement of people with disabilities in innovation processes may lower the level of required skills so that more people will find them easier to obtain and use. The basic assumption is also confirmed by the observation that the only focus group participant that used disability as an argument for or against adoption, was a disabled woman. That being said, the clearest statement articulating the need to lower required skills in new innovations was voiced in a focus group with people without disabilities. Hence, although more frequently voiced by people with disabilities, the need to lower technology skills was also acknowledged among the able consumers participating in this research.

Another observation indicating that the evaluations of people with mild forms of impairments differ from those made by people without disabilities is that moral arguments were more frequently expressed by people with disabilities, their most frequent arguments being that the product would take attention away from things that really matter in life. Interestingly, this argument was most frequently voiced by a group of men with disabilities that, in this research, stood out as more critical towards the examined product ideas than others. Involving critical consumer groups can both hinder the development of good product ideas as well as the development of unnecessary products. In a world of "economic growth", in which priority is given to the third strategy (based on the paradoxical notion that the current level of $\mathrm{CO} 2$ emissions shall be reduced through increased production; cf. Vitters $\varnothing$ et al., 2015), the importance of involving consumers hindering innovations of unnecessary products shall not be underestimated. Without such consumer groups, unnecessary products will be developeddiminishing our chance to achieve the political goal of creating a sustainable society.

An often-articulated criticism in studies of userinvolvement is that user groups tend to get involved in the innovation process too late, often in a phase where the product is already made and, therefore, hard to change. In this study, we have brought consumers in at a very early phase, in which new ideas are developing and, therefore, are in the middle of a process or change. The study indicates that people with disabilities are more engaged in this phase than people without reported disabilities in the sense that they are articulating more arguments for or/and against adoption. This is in line with previous research indicating that energy-efficient technologies are a high-engaging product for many disabled consumers, which also speaks for involving them in in- novation processes. That being said, this study has only addressed stage 1-3 of consumers' adoption process (cf. Kowalska-Pyzalska, 2018). To what extent the consumers will complete the innovation process to stage $4-5$, is therefore unknown and requires further studies.

Most studies of user-involvement have focused on developing a theoretical framework (see, for example, Etgar, 2008; Ojanen \& Hallikas, 2009) and discussions regarding benefits, challenges and reasons for engaging users in innovation processes (Elofson \& Robinson, 2007; Franke, von Hippel, \& Schreier, 2006). Many studies have been based on case-study methodologies, where one innovation is typically approached from several angles. A criticism of case studies has been that consumers are only involved in one innovation, which reduces the possibility to see how they relate to other innovations. In this study, we have explored user-involvement in many innovation processes. In all, 11 product ideas have been evaluated by people with and without reported disabilities. The study indicates that one consumer's evaluations can vary from one product to another. In some innovations, a consumer may appear as an "early adopter" accepting the product; in other innovations, she or he appears as a "non-user" rejecting it. The categorization of consumers as different types can, therefore, be difficult and should be used with caution.

Even though the evaluations of different products tend to vary, this research has indicated that some consumer groups tend to act similarly regarding more innovations. For example, men with mild disabilities seem to be more reluctant too new and efficient energy technologies than other consumer groups. The sample is, however, small, and to what extent this result can be generalized to other groups of disabled men needs to be explored in further studies.

So far, most studies of user-involvement in innovations targeting mass markets have focused on early adopters. This study has, however, brought new insight regarding non-users. Also, in this context, the observation made concerning disabled men stands out as particularly interesting. The group's main argument for turning product ideas down was that new technologies take attention away from more important things in life. Why disabled men appear to be more prone to refuse new technologies for moral reasons is one of the questions which need to be further explored should this group of consumers be followed up in further studies.

Given the large part of the population with disabilities, disenfranchisement in the form of reduced skills is seldom used as an argument against the adoption of new technologies. The tendency not to use this argument is also observed in this study, showing that the only participant using disability as an argument was a disabled woman. The tendency not to use this disability as an argument does not indicate that lack of skills is an unimportant argument in innovation processes. More likely, it indicates that low skills are not an argument that tends to be used in settings like focus groups. If 
the interviews had taken place in another setting, for example individual, face-to-face interviews that to a larger extent allow more intimate, dualistic relationships between interviewer and interviewees, disabilities might have been used more actively as an argument for and against adoption.

Last, but not least, this study has demonstrated the relevance of connecting studies of adoption processes to studies of user-involvement. Whereas studies of userinvolvement tend to focus on how different kinds of actors are involved in innovation processes, adoption studies focus on the how the innovation is received in consumer markets. As the main reason for including consumers in innovation processes is to increase the innovations' chance of success, the two fields of knowledge represent two sides of the same process. More effort should, therefore, be conducted to merge these fields of knowledge more systematically, emphasizing where the two sides complement each other and where new knowledge is needed to fill in research gaps.

\section{Conclusion}

In this study we have analyzed the role of disabled people in innovation processes based on a study exploring whether the evaluations of energy-efficient product ideas made by people with mild forms of visual, hearing, physical, and cognitive impairments differ from those given by people without reported disabilities.

The main conclusion of this article is that the research results are ambiguous. In some respect, the product evaluations of the two groups seem to be the same; in other respects, they seem different. Most importantly, the research indicates that people with disabilities seem to be more engaged in innovation processes than people without disabilities, probably due to experiences they have had by virtue of representing a group of "disadvantaged consumers" in an ablest consumer culture (Kaufman-Scarborough, 2015). It also indicates that disabled men are more likely to reject products they do not need than people without disabilities, and, hence, appear as a type of "non-use" consumers without which the political goal of creating a sustainable society will be difficult, if not impossible, to achieve. In addition, the research indicates that people with disabilities tend to use more technical arguments against adoption, their main argument being that they do not understand how the product works. This argument is, however, also voiced by people without disabilities, suggesting that this is a general problem that should be handled by means of universal solutions and design.

Overall, the research has increased our knowledge regarding the potential role of disabled people in innovation processes. That being said, the small sample explored suggests that the main conclusions of this study must be regarded as preliminary results to be confirmed or disconfirmed in future studies. Also, the conclusions cannot be generalized to other research settings, for example, research settings addressing moderately or severely disabled people (rather than mildly disabled people); innovations of food, clothes, or other products (rather than energy-efficient technologies); phase 4-5 of the innovation process (rather than phase 1-3); and innovations that will be launched in markets (rather than innovations that might be launched). Research shows that innovation processes often include researchers, businesses, and other stakeholders with different perspectives and that the relationship between the different stakeholders can be characterized by asymmetric information and power imbalances (Steel, Layton, Foster, \& Bennett, 2014). Hitherto, little is known about how processes of user involvement unfold (Geer \& Lei, 2012). Even less is known about how these processes unfold if they include people with disabilities.

\section{Acknowledgments}

Thanks to all who have contributed to this manuscript: The NATCONSUMERS consortium and the reviewers of this journal.

\section{Conflict of Interests}

The authors declare no conflict of interests.

\section{References}

Akrich, M. (1995). User representations: Practices, methods, and sociology. In J. Schot, A. Rip, \& T. Misa (Eds.), Managing technology in society: The approach of constructive technology assessment (pp. 167-184) London: Pinter.

Baker, S. M. (2006). Consumer normalcy: Understanding the value of shopping through narratives of consumers with visual impairments. Journal of Retailing, 82(1), 37-50.

Baker, S. M., Gentry, J. W., \& Rittenburg, T. L. (2005). Building understanding of the domain of consumer vulnerability. Journal of Macromarketing, 25(2), 128-139.

Bent, C., Dromacque, C., Kmetty, Z., Grigorou, R., \& Mikkelsen, T. (2017). The NATCONSUMERS handbook. A guide to introducing ICT tolls for customer engagement in energy savings. Budapest: Háttér Kiadó.

Bianchi, M., Benedetto, A., Franò, D., \& Frattini, F. (2017). Selecting early adopters to foster the diffusion of innovations in industrial markets. European of Innovation Management, 20(4), 620-644.

Borch, A., Kjørstad, I., \& Slettemeås, D. (2017). Excluding consumption practices faced by disabled people: Some preliminary results. Paper presented at the Nordic Network on Disability Research Conference, Örebro.

Borch, A., Slettemeas, D., \& Kjørstad, I. (2016a). Barrierer i funksjonshemmedes forbrukerhverdag/slik funksjonshemmedes organisasjoner ser det [Con- 
sumer barriers of disabled people: As seen from the perspective of disability organsiations] (SIFO oppdragsrapport nr. 5 - 2016). Stockholm: SIFO.

Borch, A., Kjørstad, I., \& Slettemeas, D. (2016b). Forbrukerbarrierer blant personer med nedsatt funksjonsevne. [Consumer barriers among disabled people] (Rapport no. 6). Stockholm: SIFO.

Bühler, C. (1996). Approach to the analysis of user requirements in assistive technology. International Journal of Industrial Ergonomics, 17(2), 189-192.

Chiu, H., Liu, C.-H., Hsie, C.-L., \& Li, R.-K. (2010). Essential needs and requirements of mobile phones for deaf. Assistive Technology, 22(3), 172-185.

Droge, C., Stanko, M. A., \& Pollitte, W. A. (2010). Lead users and early adopter son the web: The role of new technology product blogs. Journal of Product Innovation Management, 27(1), 66-82.

Elofson, G., \& Robinson, W. N. (2007). Collective customer collaboration impacts on supply-chain performance. International Journal of Production Research, 45(11), 2567-2594.

Etgar, M. (2008). A descriptive mode of the consumer coproduction process. Journal of the Academy and Marketing Science, 36(1), 97-198.

European Commission. (2015). Commission proposes to make products and services more accessible for disabled persons. Europa. Retrieved from europa.eu/ rapid/press-release_IP-15-6147_en.htm

Franke, N., von Hippel, E., \& Schreier, M. (2006). Finding commercially attractive user innovations; a test of lead-user theory. Journal of Product Innovation Management, 23(4), 301-315.

Geer, C. H., \& Lei, D. (2012). Collaborative innovation with customers: A review of the literature and suggestions for further research. International Journal of Management Reviews, 14(1), 63-84.

Heiskanen, E., \& Lovio, R. (2010). User-producer interaction in housing energy innovations. Energy innovations and communication challenges. Journal of Industrial Ecology, 14(1), 91-102.

Jacobsson, S., Bergek, A., \& Sandén, B. (2017). Improving the European Commission's analytical base for designing instrument mixes in the energy sector: Market failures versus system weaknesses. Energy Research \& Social Science, 33, 11-20.

Joss, N., Cooclin, A., \& Oldenburg, B. (2016). A scoping review of end user involvement in disability research. Disability and Health Journal, 9, 189-196.

Kahma, N., \& Matschoss, K. (2017). The rejection of innovations? Rethinking technology discussion and nonuse of smart energy services in Finland. Energy Research \& Social Sciences, 34, 27-36.

Kaufman-Scarborough, C. (2015). Social exclusion: A perspective on consumers with disabilities. In K. Hamilton, S. Dunett, \& M. Piacentini (Eds.), Consumer vulnerability. Conditions, contexts and characteristics. New York, NY: Routledge.

Kowalska-Pyzalska, A. (2018). What makes consumers adopt to innovative energy services in the energy market? Renewable and Sustainable Energy Reviews, 82, 3570-3581.

Mi, N., Cavuoto, L. A., Benson, K., Smith-Jackson, T., \& Nussbaum, M. A. (2014). A heuristic checklist for an accessible smartphone interface design. Journal Universal Access in the Information Society, 13(4), 351-365.

Migliaccio, G. (2016). ICT for disability management in the net economy. International Journal of Globalisation and Small Business, 8(1), 51-72.

Migliaccio, G. (2017). Disabled people in the stakeholder theory: A literature analysis. Journal of the Knowledge Economy. Advanced online publication. http://dx.doi.org/10.1007/s13132-017-0485-x

Moore, G. (1991). Inside the tornado: Marketing strategies from Silicon Valley's Cutting Edge. Chichester: Harper Business Essentials.

Noonan, T. (2007). The overlooked consumers: 20\% of the Australian population with disabilities and older people. Surry Hills: Consulting LtD: Excellence in Accessibility and Usability. Retrieved from www.humanrights.gov.au/our-work/disability-rights/ publications/overlooked-consumers-20-australianpopulation-disabilities\#_Toc176876012 (Original work published 1997)

Noppers, E. H., Keizer, K., Bolderdijk, J. W., \& Steg, L. (2014). The adoption of sustainable innovations: Driven by symbolic and environmental motives. Global Environmental Change, 25, 52-62.

Ojanen, V., \& Hallikas, J. (2009). Interorganisational routines and transformation of customer relationships in collaborative innovation. International Journal of Technology Management, 45(3/4), 306-322.

Piacentini, M., Hibbert, S., \& Hogg, M. K. (2013), Consumer resource integration amongst vulnerable consumers: Care leavers in transition to independent living. Journal of Marketing Management, 30(1/2), 201-219.

Rogers, E. M. (2003). Diffusion and innovations (5th ed.). New York, NY: Free Press.

Rohracher, H. (2003). The role of users in the social shaping of environmental technologies. Innovation, 16(2), 177-196.

Rohracher, H. (2005). From passive consumers to active participants: The diverse role of users in innovation processes. In H. Rohrachers (Ed.), User Involvement in innovation processes: Strategies and limitations from a social-technological perspective (pp. 9-35). Munich: Profil-Verlag.

Slater, D., \& Tonkiss, F. (2001). Market society. Cambridge, MA: Policy.

Snell, C., Bevan, M., \& Thomson, H. (2014). Justice, fuel poverty and disabled people in England. Energy Research \& Social Science, 10, 123-132.

Steel, E. J., Layton, N. A., Foster, M. M., \& Bennett, S. (2014) Challenges of user-centered assistive technology provision in Australia: shopping without 
a prescription. Disability and Rehabilitation. Assistive Technology, Early Online, 1-6. DOI: 10.3109/ 17483107.2014.941953.

Stewart, J., \& Habgood, V. (2008). Benefits of a health impact assessment in relation to fuel poverty. Journal of the Royal Society for the Promotion of Health, 128, 123-129.

Thomson, H. (2016). Ending energy poverty in Europe: Towards an inclusive energy union. EU Fuel Poverty Network. Retrieved from fuelpoverty.eu/ 2016/06/28/workshop-invite-ending-energy-poverty -in-europe-towards-an-inclusive-energy-union

Vitters $\varnothing$, G., Borch, A., Laitala, K., \& Strandbakken, A. (2015). Forbruk og det grønne skiftet [Consumption and the green change]. Oslo: Novus.

Von Hippel, E. (1994). Sticky information and the locus of problem solving: Implications for innovation. Management Science, 40(4), 429-439.

Von Hippel, E. (1998). Economics of product development by users: The impact of "sticky" local information. Management Service, 44(5), 629-644.

Von Hippel, E. (2005). Democratizing innovation. Cambridge, MA: MIT Press.

Ward, N., Raphael, C., Clark, R., \& Raphael, V. (2016). Involving people with profound and multiple learning disabilities in social work education: Building inclusive practices. Social Work Education, 35(8), 918-932.

Woodliffe, L. (2007). An empirical re-evaluation of consumer disadvantage. International Revue of Retail, Consumer, and Distribution Research, 12(1), 1-21.

\section{About the Authors}

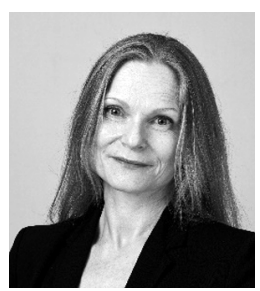

Anita Borch holds positions as Head of Research and Research Professor at Consumption Research Norway-SIFO, at Oslo Metropolitan University. She also leads an internal project at SIFO entitled "Inclusive Consumption" focusing on, among other issues, people with disabilities. Her scientific publications, since 1994, cover a range of different consumer-related subjects.

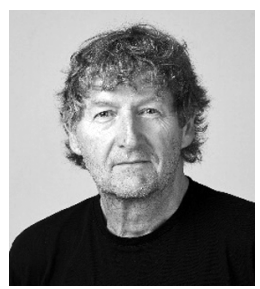

Pål Strandbakken holds a magister degree in Sociology from the University of Oslo, obtained in 1987. He holds a PhD from the University of Troms $\varnothing$, obtained in 2007, with a thesis on product durability. He is currently working as a research fellow at Consumption Research Norway-SIFO, at Oslo Metropolitan University. His main research interests are household energy consumption, material culture and sociological theory. 